\title{
O DISCURSO PERSUASIVO DO SUJEITO DAENERYS TARGARYEN EM UMA CENA DA SÉRIE TELEVISIVA “GAME OF THRONES"
}

\author{
THE PERSUASIVE SPEECH OF THE SUBJECT DAENERYS TARGARYEN \\ IN A SCENE FROM THE "GAME OF THRONES” TV SERIES
}

\author{
Carolina Fernanda Soares SILVA ${ }^{1}$ \\ Universidade Federal de Goiás \\ UFG - Campus Samambaia \\ carolfesoares@hotmail.com \\ Edna Silva FARIA ${ }^{2}$ \\ Universidade Federal de Goiás \\ UFG - Campus Samambaia
}

RESUMO Para a construção do sentido do texto, a semiótica desenvolve o seu plano de conteúdo sob a forma de um percurso gerativo, esse possui três etapas que visam compreender o discurso em seus níveis de profundidades que vão do mais simples ao mais complexo. Todo enunciado tem como objetivo persuadir o outro, mesmo que de forma explícita ou não e, na prática da comunicabilidade, o objetivo final não é apenas informar, mas persuadir o ouvinte a assentir o que está sendo proferido. A partir disso, propõe-se, neste trabalho, uma análise semiótica de uma cena presente na série de TV "Game of Thrones", objetivando analisar o percurso do destinador-manipulador, para compreender, com o apoio do material teórico a partir da teoria de Algirdas Julien Greimas nas percepções, principalmente, de Diana Luz de Pessoa Barros (2003) e José Luiz Fiorin (2008) como a personagem Daenerys Targaryen conquista um exército de Imaculados. A partir da leitura das obras, serão aplicadas no objeto de estudo as características identificáveis para o auxílio da compreensão do processo manipulatório exercido pela actante principal da cena. Por fim, a análise oferece uma reflexão acerca da persuasão presente não só neste, mas nos enunciados de um modo geral.

Palavras-chave: percurso gerativo; manipulação; semiótica.

ABSTRACT. For the construction of the meaning of the text, semiotics develops its content plan in the form of a generative path, which has three stages that aim to understand the discourse in its levels of depths ranging from the simplest to the most complex. Every statement aims to persuade the other, whether explicitly or not, and in the practice of communicability, the ultimate goal is not only to inform,

\footnotetext{
1 Mestranda do Programa de Pós-Graduação em Estudos Linguísticos da Universidade Federal de Goiás.

2 Doutora em Letras e Linguística pela Universidade Federal de Goiás. Coordenadora do Grupo de Pesquisa GESEM - Grupo de Estudos em Semiótica.
} 
but to persuade the listener to agree with what is being said. Based on this, it is proposed in this work a semiotic analysis of a scene present in the TV series "Game of Thrones", aiming at the path of the recipientmanipulator, to understand, with the support of theoretical material based on the theory of Algirdas Julien Greimas in the perceptions mainly of Diana Luz de Pessoa Barros (2003), José Luiz Fiorin (2008), Ana Cláudia de Oliveira and Eric Landowski (1995), as the character Daenerys Targaryen conquers an army of Immaculates. From the reading of the works, the identifiable characteristics will be applied to the object of study to aid the understanding, mainly of the manipulative process exercised by the main actor of the scene. Finally, the analysis offers a more intense reflection on the persuasion present not only in this one, but in the statements in general.

Keywords: generative path; manipulation; semiotic.

\section{INTRODUÇÃO}

Os sujeitos colocam-se no mundo na e pelas linguagens, verbais e/ou não e fazem da língua um fenômeno social que é demonstrado na comunicação verbal. Assim, tem-se o enunciado que é produto da enunciação e funciona como o ato de comunicar e interrelacionar o enunciador que o produz e o enunciatário que o recebe. Portanto, é necessária a compreensão, além da estrutura dos enunciados, dos aspectos extralinguísticos que os constituem. A semiótica insere-se no quadro das teorias que se atêm aos aspectos extralinguísticos do texto, por isso a utilizamos, neste trabalho, para a compreensão de uma cena enunciativa presente na série televisiva Game of Thrones. A metodologia de abordagem teórica escolhida foi a Greimaseana que permite estudar a significação como uma organização de níveis que vai do mais simples ao mais complexo, o chamado percurso gerativo de sentido. Mesmo considerando os três níveis existentes de análise, o fundamental, o narrativo e o discursivo, a proposta deste estudo é o aprofundamento dos dois primeiros níveis: o fundamental e o narrativo, que serão estudados separadamente.

O corpus em análise é dotado do exame de uma cena que tem como sujeito Daenerys Targaryen, uma das personagens principais da série de livros escritos por George R. R. Martin, As crônicas de Gelo e Fogo . Esta foi lançada em 1997 como obra escrita e, em 2011, estreou como adaptação televisiva intitulada "Game of Thrones", feita por David Benioff e D. B. Weiss que, desde a estreia, bateu recordes de audiência. A série se passa no reino de Westeros e conta com personagens históricas de características instigantes.

Desse modo, este trabalho tem como objetivo analisar o funcionamento de dois dos níveis do percurso gerativo, sendo estes o mais profundo, dito fundamental, e o intermediário, o narrativo, da significação do texto. Busca compreender, primeiramente, toda a cena enunciativa, bem como os actantes e o cenário e, em seguida, investigar como funciona a sintaxe e a semântica de cada um desses níveis na cena para, em seguida, descrever a ação de caráter persuasivo presente no discurso da personagem, fundamentando 
toda a instância enunciadora e visando ao entendimento acerca do processo manipulatório realizado pela actante principal.

\section{LINGUAGENS E ADAPTAÇÃO: DA NARRATIVA PARA A TELA}

Sob a perspectiva da semiótica francesa, conforme afirma Muniz Sodré (1988, p. 75), entende-se por narrativa o "discurso capaz de evocar, através da sucessão de fatos, um mundo dado como real ou imaginário situado num tempo e num espaço determinados." Sendo assim, dentro desse construto textual, existem diversas possibilidades de histórias que podem ser representadas de formas distintas e, também, podem ser tomadas de maneiras distintas.

O objeto de análise adotado para este trabalho consiste na adaptação de uma narrativa literária, o romance, composto por uma longa história, com a presença de muitos personagens e o aprofundamento em suas respectivas vivências. Todorov (1973) afirma que uma mesma narrativa é, além de uma história, um discurso que gera a possibilidade de reflexão vinda do leitor e pode ser apresentada por outros meios artísticos, como em filmes, por exemplo:

\footnotetext{
Ao nível mais geral, a obra literária [assim como qualquer narrativa] tem dois aspectos: ela é, ao mesmo tempo, uma história e um discurso. Ela é história, no sentido em que evoca uma certa realidade, acontecimentos que teriam ocorrido, personagens que, deste ponto de vista, se confundem com os da vida real. Esta mesma história poderia ter-nos sido relatada por outros meios; por um filme, por exemplo; ou poder-se-ia tê-la ouvido pela narrativa oral de uma testemunha, sem que fosse expressa em um livro. Mas, a obra é ao mesmo tempo discurso: existe um narrador que relata a história; há diante dele um leitor que a percebe (TODOROV, 1973, p. 211).
}

Embora o ponto de partida seja a narrativa feita em versão escrita - o livro -, neste estudo interessa a versão feita para a tv, uma "adaptação", assim nomeada pela passagem do livro para outro meio, como a televisão ou o cinema. Ballogh (1996, p.37) afirma que a "tradição consagrou o termo adaptação" para referir-se à "passagem do texto literário ao texto fílmico e/ou televisual", por sua vez, Adami (2000, p. 73) ao explorar questões que se relacionam ao processo de passagem de uma obra para outro meio, afirma que "adaptar é, principalmente, atualizar o texto em outra linguagem". Tendo em vista que, com o passar do tempo, inúmeras obras literárias foram adaptadas para o cinema e/ou televisão, diversas opiniões foram apresentadas, sejam pelos críticos ou pelo leitores/telespectadores. Dentre essas opiniões, existem polêmicas em torno de mudanças operadas no enredo e, do mesmo modo, algumas adaptações ganharam elogios e premiações, pela fidelidade à obra ou por serem consideradas, criticamente, como superior à original. Sendo assim, para se ter uma adaptação respeitável de uma obra literária, “o que realmente deve permanecer é a espinha 
dorsal do texto original, o espírito do escritor, de modo a percebermos nas entrelinhas a trama central", como pontua Adami (2000, p. 68).

A série Game of Thrones, ou GoT, como é popularmente conhecida, é o corpus deste estudo e, pela natureza complexa de sua organização - diversidade de espaço e de personagens, é importante uma breve apresentação de sua constituição. "Game of Thrones é uma série premiada produzida pela $\mathrm{HBO}^{3}$, idealizada por David Benioff e Daniel Brett Weiss. A série aborda temas fortes e diversos, dentre eles o incesto, a representação do papel feminino, religião, política, abuso sexual, escravidão, seres místicos, prostituição, homossexualidade, um universo repleto de diversidades e assuntos a serem explorados da ficção à realidade.

A narrativa tem como espaço principal um cenário semelhante à Europa medieval, o reino de Westeros, em que o inverno é anunciado pelos personagens desde o primeiro episódio e a luta pela sobrevivência inicia-se. A narrativa trata da conquista pelo Trono de Ferro, localizado na cidade de Porto Real, cuja posse garantirá a sobrevivência durante o inverno vindouro, por isso as famílias dos Sete Reinos batalham incansavelmente pela coroa.

As famílias mais influentes de Westeros e que batalham entre si são: Stark, Targaryen, Lannister, Baratheon, Greyjoy, Arryn e Tully. Cada uma dessas casas possui um escudo próprio, um lema e uma sede. Algumas casas possuem relevância sobre as outras, seja por ter posse do Trono de Ferro em algum momento da narrativa ou pela trajetória em batalhas, conquista de terras, dentre outros fatores.

Além de um enredo explorado, a narrativa também possui personagens únicos e com características marcantes, desde a figura de um anão menosprezado pela família Tyrion Lannister ${ }^{4}$, a uma rainha, Cersei Lannister ${ }^{5}$. Embora a narrativa seja constituída por inúmeras outras narrativas, a personagem enfoque deste trabalho é a enunciadora da cena a ser discutida e situa-se na família Targaryen.

Na composição da família, Daenerys Targaryen é a única e a mais nova filha do antigo rei de Westeros, Aerys Targaryen, conhecido como Rei Louco, assassinado após o Saque de Porto Real e de Rhaella Targaryen que, ao fugir do Saque, ainda grávida de Daenerys, morre logo após o parto. Daenerys tem como irmãos, o falecido Rhaegar Targaryen e Viserys Targaryen, que mais tarde também morre.

Daenerys Targaryen, no início da narrativa, apresenta-se como uma mulher frágil e dependente do irmão, Viserys, que a vende para Khal Drogo, um dos líderes do povo

3 HBO (abreviação de Home Box Office) é um canal de televisão por assinatura norte-americano. Em março de 2011, a sua programação era assistida por 28,2 milhões de assinantes nos Estados Unidos, tornando-se a segunda maior rede de canais pagos na América do Norte. Além dos EUA, a HBO é transmitida para pelo menos 50 países.

4 Com o passar da história, a personagem impõe-se perante a sociedade preconceituosa.

5 Irmã do anão, casada com o rei, Robert Baratheon, que pensa ser o pai dos filhos dela, mas na realidade, estes são filhos de Cersei e do irmão, com quem mantém um relacionamento amoroso, Jaime Lannister. 
Dothraki, para poder realizar a invasão a Westeros e conquistar o Trono de Ferro. Contudo, após o falecimento de Viserys e, posteriormente de Drogo, Daenerys passa a se impor, tornando-se uma mulher forte e resistente.

Daenerys carrega consigo os ovos de dragão que lhe foram presenteados no dia de seu casamento com Drogo, por Illyrio Mopatis, um mercador de temperos. Após o falecimento do marido, Daenerys Targaryen coloca os ovos de dragão na pira funerária do marido, lança a bruxa para morrer na pira e, em um ato inesperado, também entra nela, deixando o povo Dothraki pensar que falecera, Surpreende a todos ao sair viva do fogo e, com isso, a conhecida como mãe dos dragões passa a ser chamada de "A Não Queimada". A partir desse momento, Daenerys é venerada pelos moradores do Povo Nômade do Mar de Dothraki, que passam a apoiá-la e lutar por ela, seguindo-a na caminhada em busca do Trono de Ferro. Desse modo, Daenerys carrega consigo, em sua jornada, os filhotes de dragão: Drogon, Viserion e Rhaegal, o Khalasar - guerreiros Dothraki, e Sor Jorah, amigo e fiel escudeiro. Esse momento é um “divisor de águas” para a transição de Daenerys de mulher frágil a mulher destemida.

É inevitável dizer que a trajetória da personagem Daenerys Targaryen é marcada por diversos momentos excepcionais, mas como mencionado anteriormente, este trabalho priorizará uma cena específica. A escolha dessa cena se deu em função da importância que possui tanto para a personagem quanto para o decorrer da narrativa, pois marca uma das primeiras circunstâncias de ascensão do discurso de Daenerys, que se eleva com o amadurecimento da personagem e do poder de seus dragões, ainda filhotes.

A cena escolhida para a análise semiótica está presente na terceira temporada, no episódio quatro nominado "And now his watch is ended". Na cena, Daenerys está na cidade de Astapor, e entrega o dragão maior, Drogon, para Kraznys, um comerciante de escravos, em troca de todos os Imaculados ${ }^{7}$ para assim poder levá-los, sob sua liderança, a Porto Real, e conquistar o Trono de Ferro. Feita a troca, a actante inicia os comandos aos Imaculados, recebendo resposta assertiva e imediata. Nesse momento, ao perceber que o dragão de Daenerys está sendo hostil, Kraznys queixa-se afirmando que Drogon não obedece aos seus comandos. A partir daí, a designada "Não Queimada”, Daenerys Targaryen, pronuncia, pela primeira vez, a expressão valiriana "DRACARYS", que significa Fogo de Dragão, comando que faz com que o dragão lance fogo contra o comerciante.

Daenerys então faz um discurso libertador, deixando-os livres para segui-la. Observase, nessa trajetória, que há todo um percurso manipulador para a aceitação dos Imaculados

6 Em português: "E Agora A Vigília Dele Terminou". Tradução livre.

7 Os imaculados são escravos treinados para serem soldados puros. O treinamento é realizado de forma brutal e são tirados das mães desde a infância para se tornarem soldados "perfeitos" e no treinamento são castrados para que assim os desejos carnais não influenciem em seus atos. 
que passam a lutar por ela, A seguir, a análise semiótica da cena, passando pelo percurso gerativo de sentido, para compreensão do processo persuasivo contido nessa narrativa.

\section{O PERCURSO GERATIVO DE SENTIDO: DA OPRESSÃO À LIBERDADE}

A Semiótica greimasiana intenta precisar o momento em que um objeto se torna significante para o homem e, sendo assim, caracteriza-se por estudar os mecanismos que significam um texto, esclarecendo sobre o que " o texto diz e como faz para dizer o que diz", analisando, primeiramente, o plano de conteúdo, contemplado sob a forma de um percurso, o percurso gerativo, como aponta Barros (2003, p. 188) "a teoria semiótica procura, portanto, explicar os sentidos do texto. Para tanto, vai examinar, em primeiro lugar, os mecanismos e procedimentos de seu plano de conteúdo. O plano de conteúdo de um texto é, nesse caso, concebido, metodologicamente, sob a forma de um percurso gerativo".

Para o estudo do percurso, existem três etapas: as estruturas fundamentais, em que se estabelecem os fundamentos básicos do discurso; as estruturas narrativas, onde se situa o nível sintático-semântico intermediário; e as estruturas discursivas, mais próximas da manifestação textual. Neste trabalho, cabe a análise das estruturas fundamentais e narrativas, aprofundando a análise da cena enunciativa escolhida. Desse modo, é importante considerar que cada um desses níveis do percurso possui uma sintaxe e uma semântica, sendo que uma complementa a outra. Barros (2001, p. 16) declara que "a sintaxe semiótica deve ser considerada uma sintaxe conceptual, em que as relações, ainda que reconhecidamente abstratas, são significantes, e a semântica, uma semântica gerativa concebida sob a forma de investimentos sucessivos dos mais abstratos e não apenas taxionômica, e geral. Fiorin (1999) também explica como é o funcionamento da sintaxe e da semântica dentro da Semiótica:

\footnotetext{
Na Gramática tradicional, a sintaxe opõe-se à morfologia. Esta ocupa-se da formação das palavras e da expressão das categorias gramaticais por morfemas; aquela, da combinação de palavras para formar orações e de orações, para constituir períodos. Na Semiótica, a sintaxe contrapõe-se à semântica. Aquela é o conjunto de mecanismos que ordena os conteúdos; esta, os conteúdos investidos nos arranjos sintáticos. Observe-se, no entanto, que não se trata de uma sintaxe puramente formal, ou seja, não se opõem sintaxe e semântica como o que não é dotado de significado e o que tem significado. Um arranjo sintático é dotado de sentido. Por conseguinte, a distinção entre esses dois componentes reside no fato de que a semântica tem uma autonomia maior do que a sintaxe, o que significa que se podem investir diferentes conteúdos semânticos na mesma estrutura sintática (FIORIN, 1999 p. 167).
}

Nas estruturas fundamentais, Fiorin (2008, p. 24) afirma que "a semântica e a sintaxe do nível fundamental representam a instância inicial do percurso gerativo e procuram explicar os níveis mais abstratos da produção, do funcionamento e da interpretação do 
discurso", portanto a semântica determina os termos sustentadores do texto já "que abriga as categorias que estão na base da construção de um texto". Com isso, no nível das estruturas fundamentais são determinadas a/as oposição/ões semânticas visíveis para a construção do sentido no texto e, investigando uma oposição a $v s$. b é possível chegar à conclusão sobre qual dos elementos é positivo ou negativo ao relacionar-se com elementos da narrativa ou com a narrativa em geral. Essa contraposição de positivo e negativo, faz parte da determinação das categorias fundamentais, sendo o positivo denominado eufórico e o negativo denominado disfórico, assim cada um dos elementos da categoria de base de um texto "recebe a qualificação semântica /euforia/ - considerado um valor positivo - versus /disforia/ - visto como um valor negativo", como aponta Fiorin (2008, p. 23).

A cena de Game of Thrones a ser analisada apresenta como categoria semântica fundamental liberdade versus opressão, já que a cena se norteia, basicamente, em escravos dominados que conseguem, de certo modo, a liberdade ao se unirem por própria vontade à Daenerys, conforme se observa nas falas: "Imaculados, foram escravos a vida toda, hoje estão livres" e "Vocês lutarão por mim? Como homens livres?". Essas falas da actante remetem à oposição em que a opressão, a escravidão é algo negativo e disfórico e a liberdade, a emancipação é algo positivo e eufórico, segundo as categorias fundamentais. O quadrado semiótico abaixo organiza de forma lógica estes termos da estrutura fundamental (Ver Figura 1):

Figura 1 - Quadrado semiótico

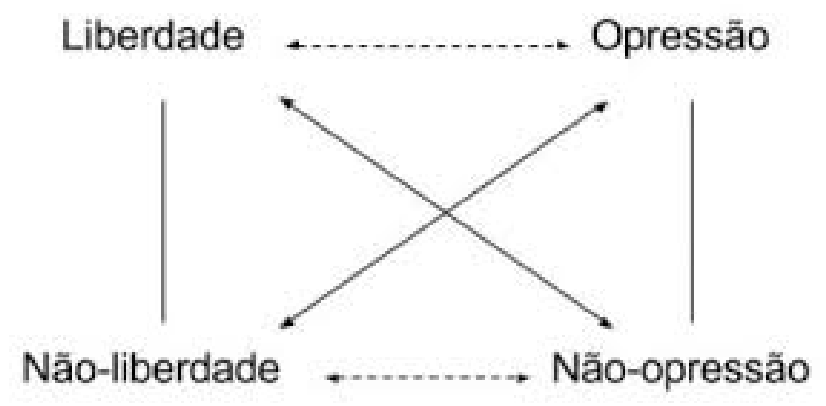

Disponível em: http://ueadsl.textolivre.pro.br/2017.2/ papers/upload/60.pdf. Acesso em: 21 ago. 2020.

A liberdade é figurativizada no dragão que, inicialmente, está preso para ser vendido e Daenerys diz a seguinte frase: "Um dragão não é um escravo", para depois, Drogon ser liberto e os outros dois dragões serem, enfaticamente, demonstrados voando no céu, numa representação da liberdade. Outro aspecto é a caracterização do céu que, antes estava aberto e ensolarado, e agora se encontra escuro e nublado, figurativizando a transformação de uma posição para a outra, ainda duvidosa quanto ao futuro: a incerteza da trajetória de 
Daenerys e seu exército, já que o céu nublado figurativiza a instabilidade e leva à dubiedade do reaparecimento do sol em sua luminosidade ou da chuva com sua melancolia.

No caso da sintaxe do nível fundamental, a negação e a asserção são as duas operações que a englobam e, como os termos devem possuir, entre si, uma relação de contrariedade, Fiorin (2008) apresenta duas relações: afirmação de A e, negação de A e afirmação de B e, afirmação de B, negação de B e afirmação de A. Por isso, empregando-se essa oposição entre disfórico e eufórico apresentada pela semântica, possui-se, no caso da cena analisada, a /liberdade/ (termo A) versus /opressão/ (termo B), ocorrendo a seguinte composição sintática fundamental: afirmação da /opressão/ com Daenerys entregando o dragão preso para o mercador de escravos; negação da /opressão/ com Daenerys dizendo ao mercador que "um dragão não é um escravo"; afirmação da /liberdade/ com a emancipação dos escravos.

No segundo estágio do percurso gerativo, o das estruturas narrativas, o que foi observado nas oposições semânticas - liberdade e opressão - é vislumbrado como valores pelos sujeitos da narrativa, deixando de ser apenas um conteúdo para ser executado pela ação do sujeito, levando esses valores a serem chamados de "objeto". Fiorin (1999, p. 05) explica que, num texto, existem dois tipos de objeto que o sujeito deseja, sendo eles; os "objetos modais (o querer, o dever, o poder e o saber), necessários para a obtenção dos objetos de valor - objetivo último da ação narrativa". Portanto, o objeto está à mercê das atitudes, determinações e investimentos realizados pelo sujeito, fazendo com que essas condutas transformem -no em um valor para esse sujeito .

O sujeito principal da narrativa é Daenerys Targaryen, cujo objeto modal é querer fingir a troca do dragão Drogon pelos escravos e a efetivação da morte do mercador Kraznys com o fogo do dragão, meios pelos quais Daenerys obterá o objeto-valor - os escravos que ajudarão a montar seu exército e não perderá uma de suas armas de manipulação - o dragão. Logo, o objeto modal de Kraznys é a proposta de troca dos seus escravos para obter um dos dragões de Daenerys, seu objeto-valor, mas não o alcança.

A fim de se compreender de maneira mais eficiente o processo narrativo, analisase, primeiramente, a sintaxe narrativa e suas características e, posteriormente, a semântica narrativa com suas nuances. A sintaxe narrativa, segundo Barros (2001, p. 28) consiste no simulacro do fazer do homem que transforma o mundo e, desse modo, "desvendar a organização narrativa" que "consiste em descrever e explicar as relações e funções do espetáculo, assim como determinar seus participantes". Oliveira e Landowski apresentam os dois tipos de enunciados elementares da sintaxe narrativa:

No nível das estruturas narrativas, as categorias fundamentais são convertidas à ordem do fazer. Trabalha-se, então, com dois tipos de enunciados elementares: 
os de estado, em que um sujeito está em relação de conjunção ou de disjunção com um objeto, e os de fazer, em que se opera uma transformação na relação entre sujeito e objeto: de disjunção para conjunção ou vice-versa. As operações de aquisição e de perda de objetos correspondem, respectivamente, à afirmação e à negação de valores no nível fundamental (OLIVEIRA; LANDOWSKI, 1995, p. 77).

A partir dessa explicação, observa-se como foi mencionado, anteriormente, que o comerciante de escravos entra em disjunção com o objeto-valor por não conseguir obtê-lo com sucesso e por morrer queimado pelo próprio objeto - o dragão. Daenerys, no início da cena, está em disjunção com seu objeto valor, pois os escravos não lhe pertencem, mas, ao final, os têm sobre seu poder, entrando em conjunção com o objeto.

Dentro de uma narrativa, existem outras narrativas mínimas. Fiorin (2008, p. 27) afirma que "a narratividade é uma transformação situada entre dois estados sucessivos e diferentes. Isso significa que ocorre uma narrativa mínima, quando se tem um estado inicial, uma transformação e um estado final." Nesse sentido, é possível perceber na cena analisada duas narrativas mínimas encaixadas: a primeira, com Daenerys sem o controle da situação dos escravos no estado inicial e, ao fim, com total poder sobre eles; e a segunda, com Daenerys fazendo com que os escravos passem do estado inicial de escravidão para o estado final de liberdade. Sendo assim, a narratividade significa uma alteração do conteúdo dentro da narrativa.

Para além dos enunciados do estado e do fazer, Fiorin (2008, p. 29) aponta que os textos também são compostos “de uma série de enunciados de fazer e de ser”. Desse modo, essas narrativas são consideradas complexas, já que os enunciados de estado (fazer e ser) estão hierarquicamente ordenados, tendo como estrutura um programa narrativo com um seguimento canônico constituído por quatro fases: manipulação, competência, performance e sanção. Esse teórico afirma, ainda, que alguns textos, apesar de serem narrativas complexas, não apresentam todas as fases da sequência canônica e/ou estão sempre em ordem. Propõe-se então a compreender o que são e se cada uma dessas fases se manifesta na cena escolhida de "GoT", iniciando com o processo de manipulação. Nesse processo, Tatit (2002, p. 191) afirma que "o que importa é o esforço do destinador no sentido de despertar a confiança do destinatário (fazer crer) para, em seguida, completar a manipulação, fazendo-o fazer ou não fazer." Assim, Fiorin estabelece $(1999$, p.5) que "essa fase pode ser concretizada como um pedido, uma súplica, uma ordem, etc".

Quando se trata de manipulação, logo se remete, no pensamento coletivo, a algo negativo, para enganar alguém, mas nem sempre se percebe que se está em um processo manipulatório o tempo todo, em diversas situações - nos elogios ou presentes ofertados a alguém, nas conversas diárias sobre sentimentos e até mesmo no bom dia enunciado 
casualmente. Nenhum dos exemplos citados é negativo e nocivo, mas manipulam, persuadem o outro, mesmo que não se perceba, a querer bem e ter uma boa visão sobre aquele que enuncia. Fiorin cita outro exemplo para explicar a relação: "Quando um pai determina que o filho lave o carro, ocorre a manipulação e o filho passa a ser um sujeito segundo o dever, embora não necessariamente segundo o querer". Fiorin ainda afirma:

a finalidade última de todo ato de comunicação não é informar, mas persuadir
o outro a aceitar o que está sendo comunicado. Por isso, o ato de comunicação é
um complexo jogo de manipulação com vistas a fazer o enunciatário crer naquilo
que se transmite. Por isso, ele é sempre persuasão. [...] A argumentação consiste
no conjunto de procedimentos linguísticos e lógicos usados pelo enunciador para
convencer o enunciatário. Por isso, não há sentido na divisão que se costuma
fazer entre discursos argumentativos, uma vez que todos visam persuadir. É claro
que alguns se assumem como explicitamente argumentativos, como discursos
publicitários, enquanto outros não se apresentam como tal, como discursos
científicos, que se mostram como discursos informativos (FIORIN, 2008, p. 75).

Desse modo, fica claro que o processo manipulatório é inerente ao ser humano e a semiótica esboça uma tipologia de manipulação de acordo com dois critérios classificatórios: o da capacidade de o manipulador para o fazer persuasivo e o da alteração modal operada na competência do sujeito manipulado. Fiorin (2008) aponta quais e como funcionam os tipos de manipulação na teoria semiótica:

Há inúmeros tipos de manipulação: o pedido, a ordem, etc. Vamos descrever apenas os quatro tipos mais comuns. Quando o manipulador propõe ao manipulado uma recompensa, ou seja, um objeto de valor positivo, com a finalidade de levá-lo a fazer alguma coisa, dá-se a tentação. Quando o manipulador o obriga a fazer por meio de ameaças, ocorre uma intimidação. Se o manipulador leva a fazer manifestando um juízo positivo sobre a competência do manipulado, há a sedução. Se ele impele à ação, exprimindo um juízo negativo a respeito da competência do manipulado, sucede uma provocação (FIORIN, 2008, p. 30).

A cena objeto desta análise possui, explicitamente, um fazer persuasivo, no qual a principal actante, Daenerys Targaryen faz com que o exército de Imaculados pertença a ela. Além do discurso que diz, é importante conhecer também todos os articuladores manipulativos utilizados por Daenerys, além da fala.

Na cena em questão, ocorre a manipulação por intimidação, quando Daenerys deixa de ser guiada pela tradução do inglês de Misandei, sua recém-aliada e passa a falar a língua Valiriana com o mercador de escravo. Ele diz para Misandei traduzir: "Diga à vadia que sua besta não obedece", falando do dragão que foi entregue ao mercador. Daenerys então revela que não precisa de tradução e que fala a língua valiriana, no momento em que o responde em valiriano: "Um dragão não é um escravo". Após isso, Kraznys, surpreendido diz para Daenerys: "Você fala valiriano?" que responde "sou Daenerys nascida da Tormenta da Casa Targaryen do sangue da Antiga Valíria, valiriano é minha língua materna”, seu 
tom de voz e sua expressão corporal ereta e elevada fazem com o que o mercador se sinta de fato intimidado. Esta intimidação oferece um valor negativo, mais do que isso, oferece uma sanção negativa a quem não aceita o contrato fiduciário.

Após esse fato, Daenerys, ao falar com os Imaculados, faz acontecer a manipulação por tentação ao pedir-lhes que eles matem quem os escravizou e então se inicia a chacina:

“- Imaculados! Matem os mestres, matem os soldados, matem todos os homens que seguram um chicote, mas não firam nenhuma criança. Rompam os grilhões de todos os escravos que virem!” O comerciante pede para que parem: “-Eu sou seu mestre. Matemna! Matem-na! Matem-na!”, mas eles não param por tentação pela liberdade ofertada. Neste momento, Daenerys diz o comando, na língua Valiriana, para que seu dragão solte fogo: "Dracarys" e solidifica seu poder já imposto na voz e na postura. Sendo assim, Daenerys também demonstra fortemente seu poder aos destinatários com o fato de ser possuidora de dragões, mais um aspecto do processo de tentação, pois tem mais força com a demonstração do poder de seu dragão, vez que demonstram imposição e dão aparato para o crescimento na cena. Todo o fato citado acima, o fingimento de que de fato trocaria um de seus dragões pelos escravos e a reviravolta ao matar o mercador com o fogo do dragão, foi um processo manipulatório planejado pela actante, em que sozinha demonstrou independência ao premeditar a ação.

Ao fim da chacina, Daenerys Targaryen é mostrada em frente ao fogo, reafirmando todo o seu poder; depois, Daenerys anda através dele e sobe em um cavalo. Caminhando com os Imaculados, ela dá seguimento ao discurso, dizendo que "eles foram escravos a vida toda e hoje estão livres". Ela assume o compromisso de deixa-los livres para partirem se quiserem, sem feri-los. Logo em seguida pergunta: "vocês lutarão por mim, sendo homens livres?" Enquanto a actante "liberta os escravos", solicita que eles a sigam e lutem por ela, o que é uma liberdade limitada. Nessa parte da cena, ocorre a manipulação por tentação, já que segundo Barros (2001, p. 38) "na tentação o manipulador mostra poder e propõe ao manipulado, para que ele faça o esperado". Barros (2001) afirma que se tem, então, a transformação da competência modal do sujeito-manipulado, que passa a querer-fazer:

O querer-fazer caracteriza a sedução e a tentação, o dever-fazer, a provocação e a intimidação. Os diferentes tipos de manipulação manifestam-se, em geral, combinados e confundidos em estruturas de manipulações complexas, que se explicam pela organização e encadeamento dos programas no percurso do destinador-manipulador (BARROS, p. 38, 2001).

Desse modo, na fase da competência, o sujeito que fará com que aconteça a mudança principal da narrativa possui um saber e ou/poder fazer. Como já exemplificado, Daenerys é dotada do saber persuasivo, com uma excelente oratória, capaz de convencer seus ouvintes. Seu poder aparece também na forma de um objeto mítico, seus dragões, uma vez que eles 
proporcionam uma imposição ainda maior da personagem, agregando valor completo nos atos de convencimento ao próximo. A partir disso, têm-se a performance, fase em que, após o sujeito demonstrar possuir o saber/fazer e/ou poder/fazer, ele age em função de seu objeto-valor e modifica a narrativa. Daenerys, demonstra sabedoria e poder ao dar ordem aos escravos para que matem quem os escravizou, ao ordenar que Drogon solte fogo para matar Kraznys e, por fim, ao conseguir o poder sobre os Imaculados, o que demonstra a performance que a actante desempenha para chegar à fase da sanção. Fiorin (2008, p. 31) aponta que a sanção é a "última fase" da manipulação. Nela ocorre a constatação de que a performance se realizou e, por conseguinte, o reconhecimento do sujeito que operou a transformação. Eventualmente, nessa fase, distribuem-se prêmios e castigos.

Daenerys consegue o esperado com o plano que arquitetou para conseguir a guarda dos Imaculados sem perder o dragão e, ainda, destruir o mercador de escravos. Sendo assim, obtém uma sanção positiva, atingindo seu objeto-valor, ou seja, o poder sobre os Imaculados. O mercador também procurou demonstrar esperteza e superioridade no início da cena, mas a sanção foi negativa, pois não possuía a competência necessária, nem realizou a performance precisa para conseguir o objeto-valor : o dragão e ficar com os escravos.

Por fim, Barros (2001, p. 33) declara que “a manipulação só será bem-sucedida quando o sistema de valores em que está assentada for compartilhado pelo manipulador e pelo manipulado, quando houver certa cumplicidade entre eles". Os soldados se manifestam e passam a seguir a actante, mudando os valores e partindo para outro caminho. Por fim, Daenerys joga a chibata no chão, figurativizando o "fim" da escravidão e o processo de manipulação da actante se concretiza. É notável que o discurso de força da interlocura atribuíse a elementos pessoais, como a forte presença e a oratória e com elementos exteriores, como a posse de dragões, fatores que figurativizam uma personagem completa. Pelo fato de terem passado toda a vida como escravos, os Imaculados desejam a liberdade, mas não a compreendem e, por isso, acreditam que lutar por alguém, sem chibatas ou palavras duras, represente a tal liberdade e que a vida gira em torno de servir algo ou alguém, a diferença é como esse serviço é realizado.

Dados os conhecimentos acerca da sintaxe narrativa, existem elementos da semântica narrativa que devem ser considerados. Observa-se que há dois tipos de objetos desejados e buscados pelos actantes na narrativa, os objetos modais (o querer, o dever, o poder e o saber) e os objetos-valor e, para consegui-los, é necessário obter e percorrer antes os primeiros. Fiorin explicita que:

É exatamente nos conteúdos investidos nos objetos que se dá a articulação entre o nível fundamental e o nível narrativo. Os conteúdos do nível fundamental são concretizados nos objetos do nível narrativo. Quando se narra a história da 
compra de um apartamento, o dinheiro que se juntou não constitui um objeto valor, mas um objeto modal, porque ele é o poder comprar (FIORIN, 1999, p. 5).

Logo, a semântica narrativa observará, de maneira superficial, a questão da modalização que, conforme Barros (2001, p. 49): “diz respeito às relações constitutivas dos enunciados e os enunciados são de dois tipos" e a das paixões advindas dela, sendo que as modalizações de enunciados são as chamadas modalização do ser e modalização do fazer, considerando que ambas possuem as quatro modalidades apresentadas acima: o querer, o dever, o poder e o saber. Ainda segundo Barros (2001, p. 43) "na modalização do fazer é preciso distinguir dois aspectos: o fazer-fazer, isto é, o fazer do destinador que comunica valores modais ao destinatário-sujeito, para que ele faça, e o ser-fazer, ou seja, a organização modal da competência do sujeito".

Sendo assim, na modalização do fazer, existem dois tipos de modalidades presentes na competência do actante: as virtualizantes, que introduzem o actante, e as atualizantes, que dão os predicados para a realização da ação na narrativa. Barros (2001, p. 43) ainda afirma que "o dever-fazer e o querer-fazer são modalidades virtualizantes, enquanto o saber-fazer e o poder-fazer são modalidades atualizantes". Na cena analisada, a atribuição da actante Daenerys no querer-fazer é demonstrada no desejo de conquistar os Imaculados antes da ação principal, ao oferecer o dragão para o mercador de escravos em troca destes e, desse modo, a competência de poder e de saber encontra-se na troca não-feita por estratégia antecipada da actante, na fala manipularória dirigida aos escravos para conquistá-los e no poder inserido nos dragões. Daenerys dispõe, portanto, dos dois tipos de modalidades essenciais para o fazer transformador, o que não ocorre com Kraznys, possuidor do quererfazer ao desejar de fato fazer a troca com Daenerys e obter o poder sobre o dragão, contudo não possui a competência do poder-fazer ao não perceber que se tratava de uma armadilha e de que perderia seus escravos, o dragão e, principalmente, a vida.

A modalização do ser visa à abordagem das paixões, a relação do sujeito com os valores. Sobre esse tipo de modalização, Barros aponta que:

Dois ângulos devem ser examinados, na modalização do ser: o da modalização veridictória, que determina a relação do sujeito com o objeto, dizendo-a verdadeira ou falsa, mentirosa ou secreta, e o da modalização pelo querer, dever, poder e saber, que incide especificamente sobre os valores investidos nos objetos (BARROS, 2001, p. 45).

O funcionamento da modalização veridictória ocorre por meio da relação /ser/vs. /parecer/ e infere-se na imanência do ser ou não-ser, em que Barros afirma: "um estado é considerado verdadeiro quando um outro sujeito, que não um modalizado, o diz verdadeiro" (2001, p. 56), ou seja, a questão em se tratar de algo verdadeiro ou falso é meramente 
interpretativa, o que, em relação à cena dessa análise, foi demonstrada através do exame feito no processo de manipulação.

É importante salientar que, nessa cena, a verdade da actante principal é figurativizada de distintas e minuciosas maneiras, já mencionadas, são elas: o tom de voz empoderado e forte da actante ao proferir seu discurso, remetendo à veracidade; o fato de fazer com que o mercador de escravos acredite na proposta de troca - um dragão pelos escravos (parece, mas não é); a postura corporal impositiva de uma verdadeira líder ao caminhar, ao subir no cavalo, ao segurar o dragão; a presença e o fato de ser possuidora de dragões também trazem verdade e poder à actante; a fala libertadora, pedindo para os escravos espontaneamente "lutarem por ela como homens livres" (parece, mas não é) e, com isso, eles passam a segui-la demonstrando que todos esses aspectos fazem com que a vejam como uma mulher confiante, destemida, verdadeira e capaz de liderá-los de forma justa e eficaz. Sobre isso, Barros nos diz:

O fazer persuasivo procura fazer-crer por meio do fazer-parecer-verdadeiro. Não se trata de produzir, de criar verdades, mas sim efeitos de verdade. O sujeito do fazer persuasivo quer levar seu destinatário a crer que o estado que apresenta parece e é verdadeiro (ou falso, etc). Realiza, portanto, uma performance cognitiva (BARROS, 2001, p. 56).

Em relação aos modalizadores do ser determinados pelo dever, querer, poder e saber, o objetivo gira em torno do objeto-valor, vez que estes constituem e transformam a existência modal dos sujeitos e também indicam a existência modal dos objetos. Essa valorização investida no objeto é caracterizada por provocar um efeito de sentido tido como passional que é compreendido, na semiótica, como qualificações modais que alteram o sujeito de estado. Barros (2001, p. 47) considera que "essas qualificações organizam-se sob a forma de arranjos sintagmáticos de modalidades ou configurações passionais". Ainda assim, existem as paixões simples e as complexas, sendo a simples resultado da alteração entre o sujeito e o objeto valor e as complexas que possuem uma complexidade de efeitos que resultam em diversos percursos passionais.

Nessa cena escolhida para a análise, cabe a paixão simples que remete à cobiça, à ambição e ao anseio dos actantes presentes na cena, resultado do querer-ser e querer-ter. Nota-se o desejo advindo tanto do mercador de escravos por possuir o poder ao obter um dragão, quanto à cobiça de Daenerys em obter seu exército de Imaculados; no caso do mercador, ele encontra a frustração por não conseguir o objeto-valor. Essa compreensão dos sentimentos dos actantes em relação ao seu objeto-valor é importante para a semântica narrativa, pois a paixão é o que controla o sujeito e impulsiona-o na realização das ações mencionadas. 


\section{CONSIDERAÇÕES FINAIS}

Este trabalho propôs-se a investigar, através do percurso gerativo de sentido, o fazer persuasivo presente em cena da série televisiva "Game of Thrones". O estudo teve como enfoque a busca pela concretização dos sentidos nos enunciados analisados, assim a narrativa foi considerada dentro das sintaxes e das semânticas de nível fundamental e narrativo. Em suma, no nível fundamental, foram localizados os valores disfóricos e eufóricos do texto e, no nível narrativo, os enunciados de estado - disjunto e conjunto, a sequência canônica completa e os usos dos objetos modais. É importante ressaltar a maneira como a narrativa se constrói para chegar à significação, através dos desdobramentos do nível fundamental, que conduz o texto para o nível narrativo, de modo que um complementa o outro.

É significativo elucidar que nem todos os conceitos da semiótica greimasiana foram agregados nesta análise, pois se crê que esta perderia a concentração nos aspectos considerados como mais importantes para o entendimento inicial da narrativa apresentada. Ainda assim, cabe ressaltar também outros elementos da semiótica que podem ser analisados em um texto, como o nível discursivo do percurso gerativo, mas acredita-se que esta análise aqui ofertada possibilita a iniciação de uma rica interlocução acerca dos assuntos tratados.

\section{REFERÊNCIAS}

ADAMI, A. O rádio e a literatura: adaptações. In LIBERO - Revista Acadêmica de Pós-graduação da Faculdade de Comunicação Social Cásper Libero, São Paulo: Cásper Libero, 2000.

BALOGH, A. M. Conjunções - disjunções - transmutações da literatura ao cinema e à TV. São Paulo: Annablume: 1996.

BARROS, D. P. Estudos do discurso. In: FIORIN, José Luiz (Org.). Introdução à Linguística II: princípios de análise. São Paulo: Contexto, 2003.

. Teoria do Discurso: Fundamentos Semióticos. São Paulo: Humanitas, 2001. . Teoria Semiótica do Texto. São Paulo: Ática, 2001.

FIORIN, J. L. Sendas e Veredas da Semiótica Narrativa e Discursiva: Towards a semiotics theory. Delta, v. 15, n. 1, Feb./July 1999.

. Elementos de Análise do Discurso. São Paulo: Contexto, 2008. . A noção de texto na Semiótica. Organon, v. 9, p.165-175, 1995.

MARTIN, G R. A Game of Thrones. New York, EUA: Bantam Dell, 1996.

SODRÉ, M. Best-seller: a literatura de mercado. São Paulo: Ática, 1988. 
TATIT, L. A abordagem do texto. In: FIORIN, José Luiz (org.). Introdução à Linguística. v.1. São Paulo: Contexto, 2002.

TODOROV, T. As Categorias da Narrativa Literária. In: Análise Estrutural da Narrativa. Tradução: Maria Zélia Barbosa Pinto. Petrópolis: Editora Vozes, 1973.

OLIVEIRA, A.; LANDOWSKI, E. Do inteligível ao sensível: em torno da obra de Algirdas Julien Greimas. São Paulo: EDUC, 1995. 